\title{
REDUCTION IN WIND FORCE IN RELATION TO CORNER DESIGN OF BRIDGE PIERS
}

\author{
Ivana Štimac Grandić ${ }^{1 *}$ - Davor Grandić ${ }^{1}$
}

${ }^{1}$ Faculty of Civil Engineering, University of Rijeka, R. Matejčić 3, Rijeka, Croatia

\begin{tabular}{l} 
ARTICLE INFO \\
\hline Article history: \\
Received: 7.2 .2019$. \\
Received in revised form: 18. 6. 2019. \\
Accepted: 19. 6. 2019. \\
\hline Keywords: \\
Wind load \\
Bridge pier \\
Corner design \\
EN 1991-1-4 \\
\hline
\end{tabular}

DOI: http://doi.org/10.30765/er.40.2.10

\section{Introduction}

Probably the best known effect of the wind on the bridges is the collapse of the Tacoma Narrows Bridge in 1940 under 40-mile-per-hour $(64 \mathrm{~km} / \mathrm{h})$ wind conditions. Although the experience of some less known bridge collapses have been used as a guide to avoid design shortcomings in new bridge projects $[1,2]$ the Tacoma Narrows bridge collapse had a lasting effect on science and engineering. Extensive research to better understand the effects of wind on bridges has been carried out since then.

The most sensitive structures to wind actions are long and flexible suspension and cable stayed bridges. It is therefore understandable that the most

\begin{abstract}
:
The effects of wind on beam bridges can be significantly reduced with careful design of deck, roadway and wind barriers, as well as with appropriate design of piers. In this paper, the influence of corner design of rectangular crosssectional piers to total wind force on piers is investigated. The total wind force changes, due to a different corner design of rectangular cross section of piers in free standing phase, are analyzed for piers of different heights, different environments and different wind velocities. The correlation between changes in total wind force and changes in geometric properties of a pier is also shown. By rounding the corners of a pier square cross section, the total wind force on pier in free standing phase can be drastically reduced in comparison to the total wind force on sharp corner pier with a small reduction in a load bearing properties of the pier. Changes in the bridge pier environment, as well as changes in pier height and wind velocity have negligible influence on changes in reduction of total wind force due to rounding the pier corners.
\end{abstract}

intensive researches have been done on these structures [2-5]. Somewhat less attention is paid to other type of bridge structures, such as continuous beam bridge structures.

Continuous bridges with high piers are usually built to span deep valleys or to cross rivers due to their economic. [6]

According to research conducted in the USA, Canada and Japan continuous precast prestressed concrete bridges are the most commonly used bridge type on interstates and high volume urban highways [7]. Similar data can be found for bridges on highways in Croatia, Italy, France, Holland and Germany [8].

\footnotetext{
* Corresponding author. Tel: 00385994149727

E-mail address: istimac@gradri.uniri.hr
} 
The effects of wind on beam bridges, can significantly be reduced with careful design of deck, roadway and wind barriers.

The significant effort in optimal design of beam and slab bridge decks especially in sense of optimization of roadway and wind barriers is done in the past years [9-11]. Unfortunately, influence of pier design to wind force on piers, according to author's knowledge is not as much investigated although Wardlaw [12] reported few cases of unexpected oscillation of bridge towers under construction.

The piers make up between $20 \%$ and $50 \%$ of the total cost of the viaduct depending on the pier heights and foundation conditions [13].

Especially sensitive to wind are piers in free standing phase just before the final connection operation take place $[12,14]$.

In the article written by Han et al. [6] the authors show contribution of different wind force components to total wind force during the longest double cantilever erection stage. The contribution of wind on piers in a total wind force is between 13\% and $46 \%$, depending on a load scenario.

From the facts written above it is clear that reduction of the wind force on piers consequently will reduce the cost of the bridge construction.

Wardlaw [12] reported that the main problem with piers and towers excitation due to wind is vortex shedding effect. Matsuzaki et al. [15] and Masaki et al. [16] studied vortex shedding effect in wind tunnel and conclude that aerodynamic corner vanes (i.e. circular arc vertical corner vanes) can eliminate the vortex shedding excitation.

In this paper the influence of corner design of rectangular cross-sectional piers to total wind force on piers in free standing phase is investigated. The total wind force on pier is calculated according to EN 1991-1-4 [17]. Although the EN 1991-1-4 gives the possibility to define parameters which are open in the Eurocode for national choice in National Annex, in this paper only the recommended procedures and values given in EN 1991-1-4 are used in calculation.

The total wind force changes due to changes in corner design of rectangular cross section are analyzed for different environments, pier heights and wind velocities.

The correlation between changes in total wind force and changes in geometric properties of piers is also shown.

\section{Definition of wind force}

The wind force $F_{w}$, according to European standard for determination of wind actions on structures [17], may be determined using the next equation:

$$
F_{w}=q_{\mathrm{p}}(z) \cdot c_{\mathrm{f}} \cdot c_{\mathrm{s}} c_{\mathrm{d}} \cdot A_{\mathrm{ref}}
$$

where $q_{\mathrm{p}}(z)$ is the peak velocity pressure at reference height $z, c_{\mathrm{f}}$ is the force coefficient for the structure or structural element, $c_{\mathrm{s}} c_{\mathrm{d}}$ is the structural factor and $A_{\text {ref }}$ is the reference area of the structural element.

The peak velocity pressure $q_{p}(z)$ at height $z$ includes mean and short-term velocity fluctuations and it is defined by:

$$
q_{\mathrm{p}}(z)=\left[1+7 \cdot I_{\mathrm{v}}(z)\right] \cdot 1 / 2 \cdot \rho \cdot v_{\mathrm{m}}^{2}(z)
$$

where $\rho$ is the air density, $I_{\mathrm{v}}(z)$ is the turbulence intensity at height $z$ and $v_{\mathrm{m}}(z)$ is the mean wind velocity at a height $z$ above the terrain.

The force coefficient $c_{f}$ is defined according to the structural element cross section (structural elements with rectangular sections, structural elements with sharp edged section, structural elements with regular polygonal section, etc.)

For structural elements with rectangular sections:

$$
c_{\mathrm{f}}=c_{\mathrm{f}, 0} \cdot \psi_{\mathrm{r}} \cdot \psi_{\chi}
$$

where $c_{\mathrm{f}, 0}$ is the force coefficient of rectangular sections with sharp corners and without free-end flow, $\psi_{\mathrm{r}}$ is the reduction factor for square sections with rounded corners and $\psi_{\chi}$ is the end-effect factor for elements with free-end flow.

The structural factor $c_{s} c_{d}$ takes into account the reduction effect on the wind action due to the no simultaneity of occurrence of the peak wind pressures on the surface $\left(c_{S}\right)$ and the increasing effect from vibrations due to turbulence in resonance with the structure $\left(c_{d}\right)$.

$$
c_{\mathrm{s}} c_{\mathrm{d}}=\frac{1+2 \cdot k_{\mathrm{p}} \cdot I_{\mathrm{v}}\left(z_{\mathrm{s}}\right) \cdot \sqrt{B^{2}+R^{2}}}{1+7 \cdot I_{\mathrm{v}}\left(z_{\mathrm{s}}\right)}
$$


where $Z_{\mathrm{s}}$ is the reference height for determining the structural factor, $k_{\mathrm{p}}$ is the peak factor, $I_{\mathrm{v}}\left(z_{\mathrm{s}}\right)$ is the turbulence intensity at the height $Z_{S}, B^{2}$ is the background factor and $R^{2}$ is the resonance response factor.

The reference area $A_{\text {ref }}$ is product of height $h$ of the structure and width $b$ of the structure or structural member perpendicular to the wind:

$$
A_{\text {ref }}=h \cdot b
$$

\section{Calculations of wind action and total wind force on pier}

Calculations of wind action and total wind force on the reinforce concrete piers in free standing phase for different corner design of rectangular crosssections shown in Fig. 1 are done. The piers are modelled as cantilever structural system (fixed in foundations and free at the top). In this research the following pier and environmental characteristic are varied: pier height $(h=20 \mathrm{~m}$ and $h=10 \mathrm{~m})$, fundamental values of the basic wind velocity (20 $\mathrm{m} / \mathrm{s}, 30 \mathrm{~m} / \mathrm{s}, 40 \mathrm{~m} / \mathrm{s}$ and $50 \mathrm{~m} / \mathrm{s}$ ), terrain categories (TC 0, TC I, TC II, TC III and TC IV according to [17]).
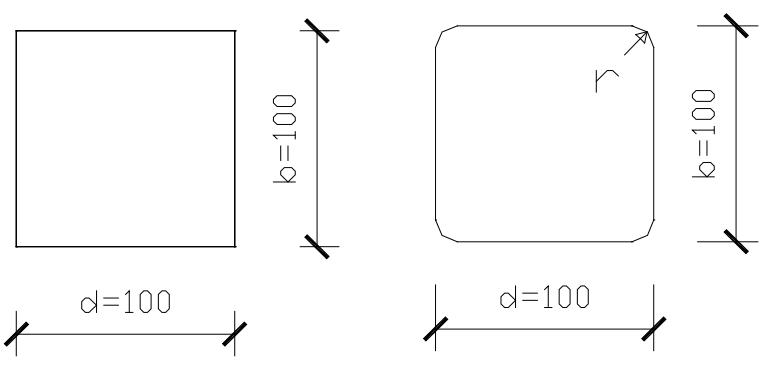

Figure 1. Cross sections of the piers (dimensions in $\mathrm{cm}$ )

The detailed calculation procedure will be presented only for the bridge piers with different corner design of following characteristic: the height of pier of $20 \mathrm{~m}$, terrain category II, and the fundamental value of the basic wind velocity of $30 \mathrm{~m} / \mathrm{s}$.

The peak velocity pressure $q_{\mathrm{p}}(z)$, at the height $z$ is determined according the equation (2).

The mean wind velocity $v_{\mathrm{m}}(z)$ at height $z$ depends on the terrain roughness and orography and on the basic wind velocity:

$$
v_{\mathrm{m}}(\mathrm{z})=c_{\mathrm{r}}(\mathrm{z}) \cdot c_{0}(\mathrm{z}) \cdot v_{\mathrm{b}}
$$

where $c_{\mathrm{r}}(z)$ is the roughness factor, $c_{0}(z)$ is the orography factor and $v_{\mathrm{b}}$ is the basic wind velocity.

The basic wind velocity $v_{b}$ shall be calculated as follows:

$$
v_{\mathrm{b}}=c_{\text {dir }} \cdot c_{\text {season }} \cdot v_{\mathrm{b}, 0} \cdot
$$

$v_{\mathrm{b}, 0}$ is the fundamental value of the basic wind velocity $(30 \mathrm{~m} / \mathrm{s}), c_{\text {dir }}$ is the directional factor (recommended value is 1 ) and $c_{\text {season }}$ is the season factor (recommended value is 1) [17]. Thus, the basic wind velocity $v_{\mathrm{b}}=30 \mathrm{~m} / \mathrm{s}$.

The recommended procedure for the determination of the roughness factor $c_{\mathrm{r}}(z)$ at height $z$ is given as:

$$
\begin{gathered}
c_{\mathrm{r}}(z)=k_{\mathrm{r}} \cdot \ln \left(z z_{0}\right) \text { for } z_{\text {min }} \leq z \leq z_{\max } \\
c_{r}(z)=c_{r}\left(z_{\text {min }}\right) \text { for } z \leq z_{\text {min }}
\end{gathered}
$$

where

$$
k_{\mathrm{r}}=0.19 \cdot\left(\frac{z_{0}}{z_{0, \mathrm{II}}}\right)^{0.07} .
$$

Table 1. Terrain categories and terrain parameters

\begin{tabular}{|c|c|c|}
\hline Terrain category & $z_{0}[\mathrm{~m}]$ & $Z_{\min }[\mathrm{m}]$ \\
\hline 0 & 0.003 & 1 \\
\hline I & 0.01 & 1 \\
\hline II & 0.05 & 2 \\
\hline III & 0.3 & 5 \\
\hline IV & 1.0 & 10 \\
\hline
\end{tabular}

The values of $z_{\min }$ and $z_{0}$ can be found in Table 1 [17], while $z_{\max }=200 \mathrm{~m}$. In the case of TC II $z_{\text {min }}=2 \mathrm{~m}, z_{0}=z_{0, \mathrm{II}}=0.05 \mathrm{~m}$. Thus $k_{\mathrm{r}}=0.19$.

The recommended value for orography factor $c_{0}(z)$ is equal to 1 [17].

The turbulence intensity $I_{\mathrm{v}}(z)$ may be determined according recommended rules as follows [17]

$$
I_{\mathrm{v}}(z)=\frac{k_{1}}{c_{0}(z) \cdot \ln z / z_{0}} \quad \text { for } z_{\min } \leq z \leq z_{\max }
$$




$$
I_{\mathrm{V}}(\mathrm{z})=I_{\mathrm{v}}\left(z_{\text {min }}\right) \text { for } \quad \mathrm{z} \leq z_{\text {min }}
$$

$k_{1}$ is the turbulence factor with recommended value of 1.0 [17].

For determination of velocity pressure of the structures where $h>2 \cdot b$ the structure has to be divided in multiple parts as shown in Fig. 1.

The bridge pier of height of $20 \mathrm{~m}$ and width of $1 \mathrm{~m}$ is divided as: the lower part extending from the ground up to $1 \mathrm{~m}$; the upper part extending from top down to $1 \mathrm{~m}$, the middle part of structure, between the upper and lower parts, divided into horizontal strips of $3 \mathrm{~m}$ height (Table 2). The velocity pressure should be assumed to be uniform over each horizontal part/strip considered. In equation (8), (9), (11) and (12) $z=z_{\mathrm{e}}$ (the reference heights $z_{e}$ are always referred to the upper heights of the corresponding structural part/strip as shown in Fig 2.)

Table 2. The peak velocity pressure $q_{p}(\mathrm{z})$ for $h=20$, TC II and $v_{b, 0}=30 \mathrm{~m} / \mathrm{s}$ in relation to $\mathrm{z}$

\begin{tabular}{|c|c|c|c|c|c|}
\hline $\begin{array}{c}z_{e} \\
{[\mathrm{~m}]}\end{array}$ & $\begin{array}{c}z \\
{[\mathrm{~m}]}\end{array}$ & $c_{r}(z)$ & $\begin{array}{c}v_{m}(z) \\
{[\mathrm{m} / \mathrm{s}]}\end{array}$ & $I_{v}(z)$ & $\begin{array}{c}q_{p}(z) \\
{\left[\mathrm{kN} / \mathrm{m}^{2}\right]}\end{array}$ \\
\hline 20 & $19-20$ & 1.138 & 34.15 & 0.167 & 1580.60 \\
\hline 19 & $16-19$ & 1.129 & 33.86 & 0.168 & 1560.88 \\
\hline 16 & $13-16$ & 1.096 & 32.88 & 0.173 & 1495.59 \\
\hline 13 & $10-13$ & 1.057 & 31.70 & 0.180 & 1418.31 \\
\hline 10 & $7-10$ & 1.007 & 30.20 & 0.189 & 1323.16 \\
\hline 7 & $4-7$ & 0.939 & 28.17 & 0.202 & 1198.30 \\
\hline 4 & $1-4$ & 0.833 & 24.98 & 0.228 & 1012.80 \\
\hline 1 & $0-1$ & 0.701 & 21.03 & 0.271 & 800.68 \\
\hline
\end{tabular}

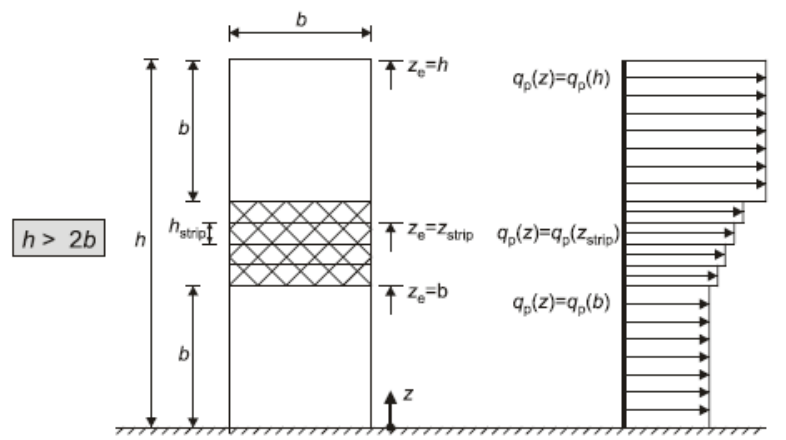

Figure 2. Reference height $z_{e}$ and corresponding velocity pressure profile [17]
Calculation of the peak velocity pressure $q_{\mathrm{p}}(z)$ is conducted for each of 8 reference heights and shown in Table 2 as well as values of $c_{\mathrm{r}}(z), v_{\mathrm{m}}(z)$ and $I_{\mathrm{v}}(\mathrm{z})$.

The force coefficient $c_{f}$ is defined by equation (3).

The force coefficient of rectangular sections with sharp corners and without free-end flow $c_{\mathrm{f}, 0}$ is defined in diagram in Fig. 4. For square shape $(d / b=1) \quad c_{\mathrm{f}, 0}=2.1$.

The reduction factors $\psi_{\mathrm{r}}$ for square sections with rounded corners are taken from Fig. 3 and presented in Table 3.

The end-effect factor $\psi_{\lambda}$ should be determined as a function of the slenderness ratio $\lambda$ and the solidity ratio $\varphi$.

For rectangular cross section of the bridge piers the slenderness ratio $\lambda$ may be determined as follows:

$$
\begin{aligned}
& h \geq 50 \mathrm{~m} \quad \lambda=1.4 \cdot h / b \text { or } \lambda=70 \\
& \text { whichever is smaller } \\
& h<15 \mathrm{~m} \lambda=2 \cdot h / b \text { or } \lambda=70 \\
& \text { whichever is smaller }
\end{aligned}
$$

For value of $h=20 \mathrm{~m}$ linear interpolation should be used $(\lambda=1.9 \cdot 20 / 1=38)$.

The solidity ratio $\varphi$ for non-hollow structures in the direction of wind action is equal to 1 . Thus, according to Fig $5, \psi_{\lambda}=0.84$.

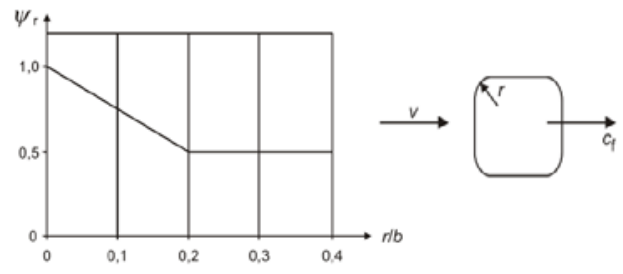

Figure 3. The reduction factor [17] 


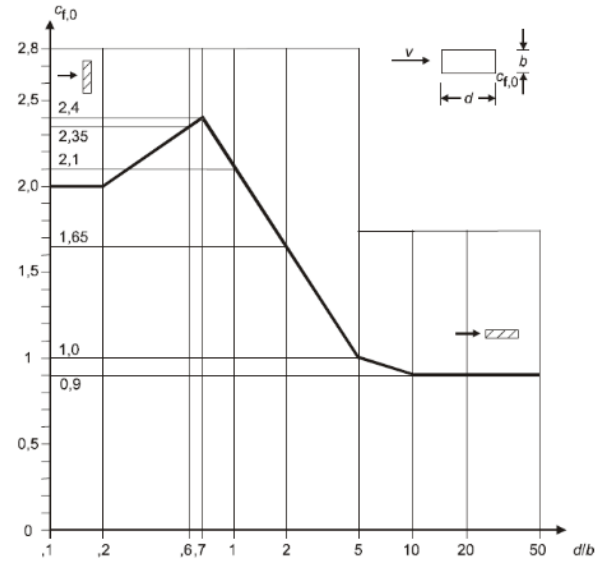

Figure 4. The force coefficient [17]

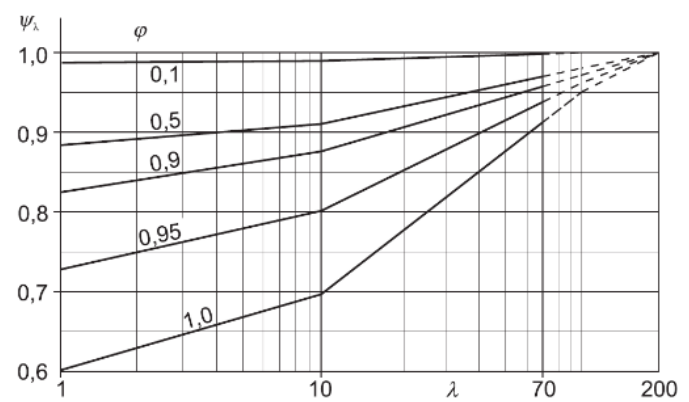

Figure 5. The end-effect factor [17]

Finally, the force coefficients $c_{\mathrm{f}}$ for pier of $h=20 \mathrm{~m}$, TC II and $v_{\mathrm{b}, 0}=30 \mathrm{~m} / \mathrm{s}$ of squared cross section $(d / b=1)$ with different corner design are shown in Table 3.

Table 3. $c_{\mathrm{f}, 0}, \psi_{\mathrm{r}}, \psi_{\lambda}, c_{f}$ in relation to $r$

\begin{tabular}{|c|c|c|c|c|}
\hline $\begin{array}{c}r \\
{[\mathrm{~cm}]}\end{array}$ & $C_{\mathrm{f}, 0}$ & $\psi_{\mathrm{r}}$ & $\psi_{\lambda}$ & $c_{f}$ \\
\hline 0 & \multirow{5}{*}{2.1} & 1.00 & \multirow{5}{*}{0.84} & 1.764 \\
\hline I & & 0.95 & & 1.676 \\
\hline II & & 0.875 & & 1.544 \\
\hline III & & 0.75 & & 1.323 \\
\hline IV & & 0.625 & & 1.103 \\
\hline
\end{tabular}

The structural factor $c_{s} c_{d}$ is to be calculated using equation (4).

According to Annex B of EN 1991-1-4 [17] the reference height $z_{\mathrm{s}}$, the peak factor $k_{\mathrm{p}}$, the turbulence intensity $I_{\mathrm{v}}\left(z_{\mathrm{S}}\right)$, the background factor $B^{2}$ and the resonance response factor $R^{2}$ are:

$$
\begin{aligned}
& \left.B^{2}=\frac{1}{1+0.9\left(\frac{b+h}{L\left(z_{\mathrm{s}}\right)}\right)}\right)^{0.63} \\
& R^{2}=\frac{\pi^{2}}{2 \cdot \delta} \cdot S_{\mathrm{L}}\left(z_{\mathrm{s}}, n_{1, \mathrm{x}}\right) \cdot R_{\mathrm{h}}\left(\mu_{\mathrm{h}}\right) \cdot R_{\mathrm{b}}\left(\mu_{\mathrm{b}}\right) \\
& I_{\mathrm{v}}\left(z_{\mathrm{S}}\right)=\frac{k_{\mathrm{l}}}{c_{0}(z) \cdot \ln \left(\frac{z_{\mathrm{s}}}{z_{0}}\right)} \\
& k_{\mathrm{p}}=\sqrt{2 \cdot \ln (v \cdot T)}+\frac{0.6}{2 \cdot \ln (v \cdot T)} \text { or } k_{\mathrm{p}}=3 \\
& \text { whichever is greater } \\
& Z_{\mathrm{S}}=0.6 \cdot h \geq z_{\text {min }} .
\end{aligned}
$$

Thus, $z_{\mathrm{s}}=12 \mathrm{~m}$ and $I_{\mathrm{v}}\left(z_{\mathrm{s}}\right)=0.182$.

The turbulent length scale $L\left(z_{\mathrm{s}}\right)$, for heights $z_{\mathrm{s}}$ above ground below $200 \mathrm{~m}$, may be calculated as follows:

$$
\begin{array}{r}
L\left(z_{\mathrm{s}}\right)=L_{\mathrm{t}} \cdot\left(\frac{z_{\mathrm{s}}}{z_{\mathrm{t}}}\right)^{\alpha} \quad \text { for } \quad z_{\min } \leq z_{\mathrm{s}} \leq z_{\max } \\
L\left(z_{\mathrm{s}}\right)=L\left(z_{\min }\right) \quad \text { for } \quad z_{\mathrm{s}}<z_{\min }
\end{array}
$$

where $\alpha=0.67+0.07 \cdot \ln \left(z_{0}\right)=0.46, \quad z_{\mathrm{t}}=200 \mathrm{~m}$ and $L_{\mathrm{t}}=300 \mathrm{~m}$. The roughness length $z_{0}=2 \mathrm{~m}$. According to Equations (20) and (21) the value of $L\left(z_{\mathrm{s}}\right)=82.169 \mathrm{~m}$. Using Equation (15) $B^{2}=0.724$. $\delta$ is the total logarithmic decrement of damping and it can be determined according to Annex F of EN 1991-1-4 [17] as:

$$
\delta=\delta_{\mathrm{s}}+\delta_{\mathrm{a}}+\delta_{\mathrm{d}}
$$

where $\delta_{\mathrm{s}}$ is the logarithmic decrement of structural damping (defined according to structural type in [17]), $\delta_{\mathrm{d}}$ is the logarithmic decrement due to special devices and $\delta_{\mathrm{a}}$ is the logarithmic decrement of aerodynamic damping defined as:

$$
\delta_{\mathrm{a}}=\frac{c_{\mathrm{f}} \cdot \rho \cdot v_{\mathrm{m}}\left(\mathrm{z}_{\mathrm{s}}\right)}{2 \cdot n \cdot m_{\mathrm{e}}} .
$$

$\rho$ is air density (taken as $1.25 \mathrm{~kg} / \mathrm{m}^{3}$ ), $m_{\mathrm{e}}$ is the mass of the structure per unit length; $n$ is the natural 
frequency of the structure. $\delta_{\mathrm{s}}$ is taken as 0.03 [17], while $\delta_{\mathrm{d}}=0$.

Module of elasticity and specific weight of reinforced concrete are taken as $E=3.2 \cdot 10^{10} \mathrm{~N} / \mathrm{m}^{2}$, $\gamma_{c}=2500 \mathrm{~kg} / \mathrm{m}^{3}$, respectively.

The values of $m_{\mathrm{e}}, n$ (determined according to [18]), and $\delta$ are shown in Table 4.

The power spectral density function is

$$
S_{\mathrm{L}}\left(z_{\mathrm{s}}, n\right)=\frac{6.8 \cdot f_{\mathrm{L}}\left(z_{\mathrm{s}}, n\right)}{\left(1+10.2 \cdot f_{\mathrm{L}}\left(z_{\mathrm{s}}, n\right)\right)^{5 / 3}}
$$

where a non-dimensional frequency $f_{\mathrm{L}}\left(z_{\mathrm{s}}, n\right)=\frac{n \cdot L\left(z_{\mathrm{s}}\right)}{v_{m}\left(z_{\mathrm{s}}\right)}$ is determined by the natural frequency of the structure $n$, by the mean velocity $v_{\mathrm{m}}\left(z_{s}\right)$ and the turbulence length scale $L\left(z_{s}\right)$.

For a fundamental mode shape $R_{\mathrm{h}}\left(\eta_{\mathrm{h}}\right)$ and $R_{\mathrm{b}}\left(\eta_{\mathrm{b}}\right)$ are:

$$
R_{\mathrm{h}}\left(\eta_{\mathrm{h}}\right)=\frac{1}{\eta_{\mathrm{h}}}-\frac{1}{2 \cdot \eta_{\mathrm{h}}{ }^{2}} \cdot\left(1-e^{-2 \cdot \eta_{\mathrm{h}}}\right)
$$

$$
R_{\mathrm{b}}\left(\eta_{\mathrm{b}}\right)=\frac{1}{\eta_{\mathrm{b}}}-\frac{1}{2 \cdot \eta_{\mathrm{b}}{ }^{2}} \cdot\left(1-e^{-2 \cdot \eta_{\mathrm{b}}}\right)
$$

where

$$
\begin{gathered}
\eta_{\mathrm{h}}=\frac{4,6 \cdot h}{L\left(s_{\mathrm{z}}\right)} \cdot f_{\mathrm{L}}\left(z_{\mathrm{s},} n\right) \\
\mu_{b}=\frac{4,6 \cdot b}{L\left(s_{\mathrm{z}}\right)} \cdot f_{\mathrm{L}}\left(z_{\mathrm{s},}, n\right) .
\end{gathered}
$$

For determination of $k_{\mathrm{p}}$ in Equation (18) it is necessary to know the averaging time for the mean wind velocity $T$ which is equal to 600 seconds [17] and the up-crossing frequency $v$ defined as:

$$
v=n \cdot \sqrt{\frac{R^{2}}{B^{2}+R^{2}}} .
$$

The values needed for calculation of structural factor $c_{s} c_{d}$ as well as the values of the structural factor itself, for pier of $\mathrm{t} h=20$, TC II and

\begin{tabular}{|c|c|c|c|c|c|}
\hline $\begin{array}{c}r \\
{[\mathrm{~cm}]}\end{array}$ & $I_{\mathrm{v}}\left(Z_{\mathrm{s}}\right)$ & $k_{\mathrm{p}}$ & $B^{2}$ & $R^{2}$ & $C_{s} C_{d}$ \\
\hline 0 & \multirow{6}{*}{0.182} & \multirow{6}{*}{3} & \multirow{6}{*}{0.724} & 1.260 & 1.116 \\
\hline 2 & & & & 1.276 & 1.119 \\
\hline 5 & & & & 1.302 & 1.123 \\
\hline 10 & & & & 1.352 & 1.132 \\
\hline 15 & & & & 1.413 & 1.142 \\
\hline 20 & & & & 1.484 & 1.154 \\
\hline
\end{tabular}
$v_{\mathrm{b}, 0}=30 \mathrm{~m} / \mathrm{s}$, can be found in Tables 4 and 5 in relation to $r$.

Table 4. The values of $m_{\mathrm{e}}, n, \delta, S_{\mathrm{L}}\left(z_{\mathrm{s}}, n\right), f_{\mathrm{L}}\left(z_{\mathrm{s}}, n\right), R_{\mathrm{h}}\left(\eta_{\mathrm{h}}\right), R_{\mathrm{b}}\left(\eta_{\mathrm{b}}\right)$ and $v$ in relation to $r$

\begin{tabular}{|c|c|c|c|c|c|c|c|c|}
\hline $\begin{array}{c}r \\
{[\mathrm{~cm}]}\end{array}$ & $\begin{array}{c}m_{\mathrm{e}} \\
{[\mathrm{kg} / \mathrm{m}]}\end{array}$ & $\begin{array}{c}n \\
{[\mathrm{~Hz}]}\end{array}$ & $\delta$ & $S_{\mathrm{L}}\left(z_{\mathrm{s}}, n\right)$ & $f_{\mathrm{L}}\left(z_{\mathrm{s}}, n\right)$ & $R_{\mathrm{h}}\left(\eta_{\mathrm{h}}\right)$ & $R_{\mathrm{b}}\left(\eta_{\mathrm{b}}\right)$ & $\begin{array}{c}v \\
{[\mathrm{~Hz}]}\end{array}$ \\
\hline 0 & 2500 & 1.445 & 0.040 & 0.056 & 3.800 & 0.207 & 0.872 & 1.151 \\
\hline 2 & 2499 & 1.444 & 0.039 & 0.056 & 3.797 & 0.208 & 0.872 & 1.153 \\
\hline 5 & 2495 & 1.442 & 0.038 & 0.056 & 3.792 & 0.208 & 0.872 & 1.156 \\
\hline 10 & 2479 & 1.434 & 0.037 & 0.056 & 3.772 & 0.209 & 0.873 & 1.157 \\
\hline 15 & 2452 & 1.421 & 0.036 & 0.056 & 3.738 & 0.210 & 0.874 & 1.156 \\
\hline 20 & 2414 & 1.406 & 0.035 & 0.057 & 3.698 & 0.212 & 0.875 & 1.152 \\
\hline
\end{tabular}

Table 5. The values of $I_{\mathrm{v}}\left(z_{\mathrm{s}}\right), k_{\mathrm{p}}, B^{2}, R^{2}$ and $c_{s} c_{d}$ in relation to $r$ 
For total wind force calculation, it is necessary to determine the wind pressure $q_{w}(z)$ for each part/strip according to Table 2 and Fig. 1.

$$
q_{w}(z)=c_{s} c_{d} \cdot c_{f} \cdot q_{p}(z) \cdot b
$$

The values of $q_{w}(z)$ in relation to $z$ are presented in Table 6.

The total wind force on pier $F_{w}$ is the sum of wind forces acting in each part/strip $F_{w}(z)$ :

$$
F_{w}=\sum F_{w}(z)=\sum q_{w}(z) \cdot b \cdot h_{p a r t}
$$

where $h_{\text {part }}$ is the height of each part (b) or strip $\left(h_{\text {strip }}\right)$ according to Fig. 3.

The total wind forces $F_{w}$ on piers of different heights, placed in different environmental (TC) and exposed to different fundamental value of the basic wind velocity are calculated according to the previous procedure. The results are shown in Tables 7 and 8.

Table 6. Wind pressure $q_{w}(z)$ on pier of $h=20 \mathrm{~m}$, TC II and $v_{b, 0}=30 \mathrm{~m} / \mathrm{s}$ in relation to $\mathrm{r}$ and $\mathrm{z}$

\begin{tabular}{|c|c|c|c|c|c|c|c|c|c|}
\hline \multicolumn{2}{|c|}{$\begin{array}{c}q_{w}(z) \\
{[\mathrm{kN} / \mathrm{m}]}\end{array}$} & \multicolumn{9}{|c|}{$z[\mathrm{~m}]$} \\
\cline { 2 - 10 } & $0-1$ & $1-4$ & $4-7$ & $7-10$ & $10-13$ & $13-16$ & $16-19$ & $19-21$ \\
\hline \multirow{4}{*}{$r$} & 0 & 1.58 & 1.99 & 2.36 & 2.61 & 2.79 & 2.94 & 3.07 & 3.11 \\
\cline { 2 - 10 } & 2 & 1.50 & 1.90 & 2.25 & 2.48 & 2.66 & 2.80 & 2.93 & 2.96 \\
\cline { 2 - 10 }$[\mathrm{cm}]$ & 5 & 1.39 & 1.75 & 2.08 & 2.29 & 2.46 & 2.59 & 2.70 & 2.74 \\
\cline { 2 - 10 } & 10 & 1.20 & 1.52 & 1.80 & 1.98 & 2.13 & 2.24 & 2.34 & 2.37 \\
\cline { 2 - 10 } & 15 & 1.01 & 1.28 & 1.51 & 1.67 & 1.79 & 1.88 & 1.97 & 1.99 \\
\cline { 2 - 10 } & 20 & 0.81 & 1.03 & 1.22 & 1.35 & 1.44 & 1.52 & 1.59 & 1.61 \\
\hline
\end{tabular}

Table 7. Total wind force $F_{w}$ on pier of $h=20 \mathrm{~m}$ in relation to $r$

\begin{tabular}{|c|l|r|r|r|r|r|r|}
\hline \multicolumn{2}{|c|}{$F_{\mathrm{w}}[\mathrm{kN}]$} & $r=0$ & $r=2 \mathrm{~cm}$ & $r=5 \mathrm{~cm}$ & $r=10 \mathrm{~cm}$ & $r=15 \mathrm{~cm}$ & $r=20 \mathrm{~cm}$ \\
\hline \multirow{4}{*}{ TC 0 } & $v_{b .0}=20 \mathrm{~m} / \mathrm{s}$ & 26.56 & 25.26 & 23.31 & 20.06 & 16.79 & 13.50 \\
\cline { 2 - 8 } & $v_{b .0}=30 \mathrm{~m} / \mathrm{s}$ & 64.27 & 61.19 & 56.56 & 48.81 & 41.00 & 33.09 \\
\cline { 2 - 8 } & $v_{b .0}=40 \mathrm{~m} / \mathrm{s}$ & 121.07 & 115.40 & 106.84 & 92.45 & 77.89 & 63.08 \\
\cline { 2 - 8 } & $v_{b .0}=50 \mathrm{~m} / \mathrm{s}$ & 197.97 & 188.86 & 175.09 & 151.88 & 128.31 & 104.24 \\
\hline \multirow{5}{*}{ TC I } & $v_{b .0}=20 \mathrm{~m} / \mathrm{s}$ & 24.67 & 23.47 & 21.66 & 18.64 & 15.62 & 12.56 \\
\cline { 2 - 8 } & $v_{b .0}=30 \mathrm{~m} / \mathrm{s}$ & 60.36 & 57.48 & 53.15 & 45.88 & 38.56 & 31.15 \\
\cline { 2 - 8 } & $v_{b .0}=40 \mathrm{~m} / \mathrm{s}$ & 114.69 & 109.33 & 101.25 & 87.67 & 73.92 & 59.91 \\
\cline { 2 - 8 } & $v_{b .0}=50 \mathrm{~m} / \mathrm{s}$ & 188.78 & 180.14 & 167.07 & 145.03 & 122.62 & 99.71 \\
\hline \multirow{5}{*}{ TC II } & $v_{b .0}=20 \mathrm{~m} / \mathrm{s}$ & 20.94 & 19.92 & 18.38 & 15.82 & 13.26 & 10.67 \\
\cline { 2 - 8 } & $v_{b .0}=30 \mathrm{~m} / \mathrm{s}$ & 52.00 & 49.52 & 45.79 & 39.55 & 33.25 & 26.87 \\
\cline { 2 - 8 } & $v_{b .0}=40 \mathrm{~m} / \mathrm{s}$ & 100.06 & 95.40 & 88.37 & 76.54 & 64.56 & 52.36 \\
\cline { 2 - 8 } & $v_{b .0}=50 \mathrm{~m} / \mathrm{s}$ & 166.44 & 158.84 & 147.35 & 127.97 & 108.26 & 88.07 \\
\hline \multirow{5}{*}{ TC III } & $v_{b .0}=20 \mathrm{~m} / \mathrm{s}$ & 14.98 & 14.25 & 13.15 & 11.31 & 9.47 & 7.62 \\
\cline { 2 - 8 } & $v_{b .0}=30 \mathrm{~m} / \mathrm{s}$ & 37.75 & 35.94 & 33.22 & 28.67 & 24.10 & 19.46 \\
\cline { 2 - 8 } & $v_{b .0}=40 \mathrm{~m} / \mathrm{s}$ & 73.73 & 70.28 & 65.06 & 56.31 & 47.47 & 38.47 \\
\cline { 2 - 8 } & $v_{b .0}=50 \mathrm{~m} / \mathrm{s}$ & 124.36 & 118.64 & 110.00 & 95.46 & 80.69 & 65.59 \\
\hline \multirow{5}{*}{ TC IV } & $v_{b .0}=20 \mathrm{~m} / \mathrm{s}$ & 10.63 & 10.11 & 9.32 & 8.01 & 6.71 & 5.39 \\
\cline { 2 - 8 } & $v_{b .0}=30 \mathrm{~m} / \mathrm{s}$ & 26.82 & 25.52 & 23.57 & 20.32 & 17.05 & 13.75 \\
\cline { 2 - 8 } & $v_{b .0}=40 \mathrm{~m} / \mathrm{s}$ & 52.74 & 50.23 & 46.46 & 40.15 & 33.78 & 27.33 \\
\cline { 2 - 8 } & $v_{b .0}=50 \mathrm{~m} / \mathrm{s}$ & 89.74 & 85.55 & 79.23 & 68.62 & 57.89 & 46.96 \\
\hline
\end{tabular}


Table 8. Total wind force $F_{w}$ on pier of $h=10 \mathrm{~m}$ in relation to $r$

\begin{tabular}{|c|c|c|c|c|c|c|c|}
\hline \multicolumn{2}{|c|}{$F_{w}[\mathrm{kN}]$} & $r=0$ & $r=2 \mathrm{~cm}$ & $r=5 \mathrm{~cm}$ & $r=10 \mathrm{~cm}$ & $r=15 \mathrm{~cm}$ & $r=20 \mathrm{~cm}$ \\
\hline \multirow{4}{*}{ TC 0} & $v_{b .0}=20 \mathrm{~m} / \mathrm{s}$ & 9.80 & 9.31 & 8.57 & 7.35 & 6.13 & 4.91 \\
\hline & $v_{b .0}=30 \mathrm{~m} / \mathrm{s}$ & 22.81 & 21.68 & 19.98 & 17.14 & 14.31 & 11.46 \\
\hline & $v_{b .0}=40 \mathrm{~m} / \mathrm{s}$ & 42.90 & 40.78 & 37.59 & 32.28 & 26.96 & 21.63 \\
\hline & $v_{b .0}=50 \mathrm{~m} / \mathrm{s}$ & 70.53 & 67.06 & 61.85 & 53.16 & 44.44 & 35.69 \\
\hline \multirow{4}{*}{ TC I } & $v_{b .0}=20 \mathrm{~m} / \mathrm{s}$ & 8.78 & 8.34 & 7.69 & 6.59 & 5.50 & 4.40 \\
\hline & $v_{b .0}=30 \mathrm{~m} / \mathrm{s}$ & 20.58 & 19.55 & 18.02 & 15.46 & 12.91 & 10.35 \\
\hline & $v_{b .0}=40 \mathrm{~m} / \mathrm{s}$ & 38.98 & 37.05 & 34.16 & 29.34 & 24.51 & 19.67 \\
\hline & $v_{b .0}=50 \mathrm{~m} / \mathrm{s}$ & 64.54 & 61.36 & 56.60 & 48.65 & 40.69 & 32.69 \\
\hline \multirow{4}{*}{ TC II } & $v_{b .0}=20 \mathrm{~m} / \mathrm{s}$ & 7.08 & 6.73 & 6.20 & 5.31 & 4.43 & 3.55 \\
\hline & $v_{b .0}=30 \mathrm{~m} / \mathrm{s}$ & 16.66 & 15.83 & 14.59 & 12.52 & 10.45 & 8.38 \\
\hline & $v_{b .0}=40 \mathrm{~m} / \mathrm{s}$ & 31.87 & 30.29 & 27.93 & 23.99 & 20.04 & 16.09 \\
\hline & $v_{b .0}=50 \mathrm{~m} / \mathrm{s}$ & 53.24 & 50.62 & 46.69 & 40.14 & 33.57 & 26.98 \\
\hline \multirow{4}{*}{ TC III } & $v_{b .0}=20 \mathrm{~m} / \mathrm{s}$ & 4.85 & 4.60 & 4.24 & 3.64 & 3.03 & 2.43 \\
\hline & $v_{b .0}=30 \mathrm{~m} / \mathrm{s}$ & 11.28 & 10.72 & 9.88 & 8.47 & 7.07 & 5.67 \\
\hline & $v_{b .0}=40 \mathrm{~m} / \mathrm{s}$ & 21.68 & 20.60 & 18.99 & 16.30 & 13.62 & 10.93 \\
\hline & $v_{b .0}=50 \mathrm{~m} / \mathrm{s}$ & 36.42 & 34.62 & 31.92 & 27.43 & 22.94 & 18.42 \\
\hline \multirow{4}{*}{ TC IV } & $v_{b .0}=20 \mathrm{~m} / \mathrm{s}$ & 3.71 & 3.53 & 3.25 & 2.79 & 2.32 & 1.86 \\
\hline & $v_{b .0}=30 \mathrm{~m} / \mathrm{s}$ & 8.54 & 8.11 & 7.47 & 6.41 & 5.35 & 4.28 \\
\hline & $v_{b .0}=40 \mathrm{~m} / \mathrm{s}$ & 8.54 & 8.11 & 7.47 & 6.41 & 5.35 & 4.28 \\
\hline & $v_{b .0}=50 \mathrm{~m} / \mathrm{s}$ & 26.66 & 25.34 & 23.35 & 20.05 & 16.75 & 13.44 \\
\hline
\end{tabular}

\section{Discussion}

As it can be seen from the results shown in Tables 7 and 8 the total wind force for cross sections with round corners is smaller than for sharp corners. For greater corner radius the reduction of total wind force in relation to sharp corner cross section is greater. For easier comparison, the total wind force reduction $\Delta F_{w(r)}=1-\left(F_{w(r)} / F_{w(r=0)}\right)[\%]$ is shown in Tables 9 and $10\left(F_{w(r=0)}\right.$ is total wind force for pier with sharp corners and $F_{w(r)}$ is total wind force for pier with rounded corners).

Rounding of sharp corners of square piers may reduce the total wind force significantly (see Fig. 68). According to Table 9 the total wind force on pier of $20 \mathrm{~m}$ height with rounded corners of $r=2 \mathrm{~cm}$ is smaller between $4.6 \%$ and $4.9 \%$ in comparison to total wind force on pier with sharp corners. If $r=5$ $\mathrm{cm}$ the reduction in total wind force is between $11.5 \%$ and $12.3 \%$. In case of rounded corners with $r=10 \mathrm{~cm}, r=15 \mathrm{~cm}$ and $r=20 \mathrm{~cm}$ the reduction in total wind force is as follows: $\Delta F_{w(r=10)}$ from $23.1 \%$ to $24.6 \% ; \Delta F_{w(r=15)}$ from $35 \%$ to $36.9 \%$; $\Delta F_{w(r=20)}$ from $47.1 \%$ to $49.3 \%$.
Similar results can be found in Table 10 for pier of $10 \mathrm{~m}$ height: $\Delta F_{w(r=2)}$ is in range from $4.9 \%$ to $5.0 \%$; $\Delta F_{w(r=5)}$ from $12.3 \%$ to $12.5 \%$; $\Delta F_{w(r=10)}$ from $24.6 \%$ to $25.0 \% ; \Delta F_{w(r=15)}$ from $36.9 \%$ to $37.5 \% ; \Delta F_{w(r=20)}$ from $49.3 \%$ to $49.9 \%$.

Comparing the results shown in the Tables 9 and 10, it can be seen there is small influence of different pier height on reduction in total wind force (the changes in total wind force reduction due to changes of pier height are in range of $0.1 \%$ to $2.2 \%$ ). For shorter pier the reduction of total wind force is greater (see Fig. 8).

The influence of different wind velocity and different terrain category on reduction of total wind force are relatively small.

The increase in wind velocity decreases the total wind force reduction as it is shown in Fig. 6. Decrease in the total wind force reduction due to changes in wind velocity is greater for piers of $20 \mathrm{~m}$ height than for piers of $10 \mathrm{~m}$ height. The smallest difference in reduction in total wind force due to different wind velocity for piers of height of $20 \mathrm{~m}$ is in case of $r=2 \mathrm{~cm}$ and TC 0 , TC I, TC II and TC III $(0.3 \%)$ while the greatest difference is for piers with 
$r=20 \mathrm{~cm}$ placed in TC 0 , TC I and TC II $(1.9 \%)$ as it can be seen in Table 9. As it is shown in Table 10, even smaller differences in reduction in total wind force due to changes in wind velocity are for piers of height of $10 \mathrm{~m}$ (up to $0.6 \%$ ).

There is almost no changes in total wind force reduction with changing of the pier environment, here expressed as different terrain categories (TC) as it can be seen from Fig. 7 and Tables 9 and 10. For example, in case of pier of height of $20 \mathrm{~m}$ with rounded corners of $r=2 \mathrm{~cm}$ exposed to $v_{b, 0}=20 \mathrm{~m} / \mathrm{s}$ and $v_{b, 0}=30 \mathrm{~m} / \mathrm{s}$ the reduction in total wind force due to changes in terrain category do not varies at all, while for the same pier exposed to $v_{b, 0}=40 \mathrm{~m} / \mathrm{s}$ and $v_{b, 0}=50 \mathrm{~m} / \mathrm{s}$ the reduction in total wind force varies $0.1 \%$.

The greatest variation in the total wind force reduction due to different terrain categories is in case of pier of height of $20 \mathrm{~m}$ with rounded corners of $r=20 \mathrm{~cm}$ exposed to $v_{b, 0}=50 \mathrm{~m} / \mathrm{s}(0.6 \%)$. For pier of height of $10 \mathrm{~m} 0.3 \%$ is the greatest difference in total wind force reduction due to different terrain categories.

Although piers with rounded corners analysed in this paper can be exposed up to $50 \%$ smaller total wind force in comparison to sharp corner piers, the piers with rounded corners have smaller area and moment of inertia, which are the main load bearing properties of pier.

The total wind force reduction in correlation to reduction in load baring properties of sharp and rounded corner pier cross sections is presented in Table 11. The reduction of area is $\Delta A_{(r)}=1-\left(A_{(r)}\right.$ $/ A_{(r=0)}$ [\%], where $A_{(r=0)}$ is area of sharp corner cross section and $A_{(r)}$ is area of cross section with rounded corner, while the reduction of moment of inertia is $\Delta I_{(r)}=1-\left(I_{(r)} / I_{(r=0)}\right)[\%]$, where $I_{(r=0)}$ is moment of inertia of sharp corner cross section and $I_{(r)}$ is moment of inertia of cross section with rounded corner.

Table 9. Reduction in total wind force $\Delta F_{w(r)}[\%]$ on pier of $h=20 \mathrm{~m}$ in relation to $r$

\begin{tabular}{|c|l|r|r|r|r|r|}
\hline \multicolumn{2}{|c|}{$\Delta F_{w(r)}[\%]$} & $r=2 \mathrm{~cm}$ & $r=5 \mathrm{~cm}$ & $r=10 \mathrm{~cm}$ & $r=15 \mathrm{~cm}$ & $r=20 \mathrm{~cm}$ \\
\hline \multirow{4}{*}{ TC 0 } & $v_{b .0}=20 \mathrm{~m} / \mathrm{s}$ & 4.9 & 12.2 & 24.5 & 36.8 & 49.2 \\
\cline { 2 - 7 } & $v_{b .0}=30 \mathrm{~m} / \mathrm{s}$ & 4.8 & 12.0 & 24.0 & 36.2 & 48.5 \\
\cline { 2 - 7 } & $v_{b .0}=40 \mathrm{~m} / \mathrm{s}$ & 4.7 & 11.8 & 23.6 & 35.7 & 47.9 \\
\cline { 2 - 7 } & $v_{b .0}=50 \mathrm{~m} / \mathrm{s}$ & 4.6 & 11.6 & 23.3 & 35.2 & 47.3 \\
\hline \multirow{4}{*}{ TC I } & $v_{b .0}=20 \mathrm{~m} / \mathrm{s}$ & 4.9 & 12.2 & 24.4 & 36.7 & 49.1 \\
\cline { 2 - 7 } & $v_{b .0}=30 \mathrm{~m} / \mathrm{s}$ & 4.8 & 11.9 & 24.0 & 36.1 & 48.4 \\
\cline { 2 - 7 } & $v_{b .0}=40 \mathrm{~m} / \mathrm{s}$ & 4.7 & 11.7 & 23.6 & 35.5 & 47.8 \\
\cline { 2 - 7 } & $v_{b .0}=50 \mathrm{~m} / \mathrm{s}$ & 4.6 & 11.5 & 23.2 & 35.0 & 47.2 \\
\hline \multirow{4}{*}{ TC II } & $v_{b .0}=20 \mathrm{~m} / \mathrm{s}$ & 4.9 & 12.2 & 24.4 & 36.7 & 49.0 \\
\cline { 2 - 7 } & $v_{b .0}=30 \mathrm{~m} / \mathrm{s}$ & 4.8 & 11.9 & 23.9 & 36.1 & 48.3 \\
\cline { 2 - 7 } & $v_{b .0}=40 \mathrm{~m} / \mathrm{s}$ & 4.7 & 11.7 & 23.5 & 35.5 & 47.7 \\
\cline { 2 - 7 } & $v_{b .0}=50 \mathrm{~m} / \mathrm{s}$ & 4.6 & 11.5 & 23.1 & 35.0 & 47.1 \\
\hline \multirow{5}{*}{ TC III } & $v_{b .0}=20 \mathrm{~m} / \mathrm{s}$ & 4.9 & 12.2 & 24.5 & 36.8 & 49.1 \\
\cline { 2 - 7 } & $v_{b .0}=30 \mathrm{~m} / \mathrm{s}$ & 4.8 & 12.0 & 24.0 & 36.2 & 48.4 \\
\cline { 2 - 7 } & $v_{b .0}=40 \mathrm{~m} / \mathrm{s}$ & 4.7 & 11.8 & 23.6 & 35.6 & 47.8 \\
\cline { 2 - 7 } & $v_{b .0}=50 \mathrm{~m} / \mathrm{s}$ & 4.6 & 11.5 & 23.2 & 35.1 & 47.3 \\
\hline \multirow{5}{*}{ TC IV } & $v_{b .0}=20 \mathrm{~m} / \mathrm{s}$ & 4.9 & 12.3 & 24.6 & 36.9 & 49.3 \\
\cline { 2 - 7 } & $v_{b .0}=30 \mathrm{~m} / \mathrm{s}$ & 4.8 & 12.1 & 24.2 & 36.4 & 48.7 \\
\cline { 2 - 7 } & $v_{b .0}=40 \mathrm{~m} / \mathrm{s}$ & 4.8 & 11.9 & 23.9 & 35.9 & 48.2 \\
\cline { 2 - 7 } & $v_{b .0}=50 \mathrm{~m} / \mathrm{s}$ & 4.7 & 11.7 & 23.5 & 35.5 & 47.7 \\
\hline
\end{tabular}


Table 10. Reduction in total wind force $\Delta F_{w(r)}[\%]$ on pier of $h=10 \mathrm{~m}$ in relation to $r$

\begin{tabular}{|c|l|r|r|r|r|r|}
\hline \multicolumn{2}{|c|}{$\Delta F_{w(r)}[\%]$} & $r=2 \mathrm{~cm}$ & $r=5 \mathrm{~cm}$ & $r=10 \mathrm{~cm}$ & $r=15 \mathrm{~cm}$ & $r=20 \mathrm{~cm}$ \\
\hline \multirow{4}{*}{ TC 0 } & $v_{b .0}=20 \mathrm{~m} / \mathrm{s}$ & 5.0 & 12.5 & 24.9 & 37.4 & 49.9 \\
\cline { 2 - 7 } & $v_{b .0}=30 \mathrm{~m} / \mathrm{s}$ & 5.0 & 12.4 & 24.9 & 37.3 & 49.7 \\
\cline { 2 - 7 } & $v_{b .0}=40 \mathrm{~m} / \mathrm{s}$ & 4.9 & 12.4 & 24.8 & 37.1 & 49.6 \\
\cline { 2 - 7 } & $v_{b .0}=50 \mathrm{~m} / \mathrm{s}$ & 4.9 & 12.3 & 24.6 & 37.0 & 49.4 \\
\hline \multirow{4}{*}{ TC I } & $v_{b .0}=20 \mathrm{~m} / \mathrm{s}$ & 5.0 & 12.5 & 24.9 & 37.4 & 49.9 \\
\cline { 2 - 7 } & $v_{b .0}=30 \mathrm{~m} / \mathrm{s}$ & 5.0 & 12.4 & 24.8 & 37.3 & 49.7 \\
\cline { 2 - 7 } & $v_{b .0}=40 \mathrm{~m} / \mathrm{s}$ & 4.9 & 12.4 & 24.7 & 37.1 & 49.5 \\
\cline { 2 - 7 } & $v_{b .0}=50 \mathrm{~m} / \mathrm{s}$ & 4.9 & 12.3 & 24.6 & 36.9 & 49.3 \\
\hline \multirow{4}{*}{ TC II } & $v_{b .0}=20 \mathrm{~m} / \mathrm{s}$ & 5.0 & 12.5 & 24.9 & 37.4 & 49.9 \\
\cline { 2 - 7 } & $v_{b .0}=30 \mathrm{~m} / \mathrm{s}$ & 5.0 & 12.4 & 24.8 & 37.3 & 49.7 \\
\cline { 2 - 7 } & $v_{b .0}=40 \mathrm{~m} / \mathrm{s}$ & 4.9 & 12.4 & 24.7 & 37.1 & 49.5 \\
\cline { 2 - 7 } & $v_{b .0}=50 \mathrm{~m} / \mathrm{s}$ & 4.9 & 12.3 & 24.6 & 36.9 & 49.3 \\
\hline \multirow{5}{*}{ TC III } & $v_{b .0}=20 \mathrm{~m} / \mathrm{s}$ & 5.0 & 12.5 & 25.0 & 37.4 & 49.9 \\
\cline { 2 - 7 } & $v_{b .0}=30 \mathrm{~m} / \mathrm{s}$ & 5.0 & 12.5 & 24.9 & 37.3 & 49.8 \\
\cline { 2 - 7 } & $v_{b .0}=40 \mathrm{~m} / \mathrm{s}$ & 5.0 & 12.4 & 24.8 & 37.2 & 49.6 \\
\cline { 2 - 7 } & $v_{b .0}=50 \mathrm{~m} / \mathrm{s}$ & 4.9 & 12.3 & 24.7 & 37.0 & 49.4 \\
\hline \multirow{5}{*}{ TC IV } & $v_{b .0}=20 \mathrm{~m} / \mathrm{s}$ & 5.0 & 12.5 & 25.0 & 37.5 & 49.9 \\
\cline { 2 - 7 } & $v_{b .0}=30 \mathrm{~m} / \mathrm{s}$ & 5.0 & 12.5 & 24.9 & 37.4 & 49.9 \\
\cline { 2 - 7 } & $v_{b .0}=40 \mathrm{~m} / \mathrm{s}$ & 5.0 & 12.5 & 24.9 & 37.4 & 49.9 \\
\cline { 2 - 7 } & $v_{b .0}=50 \mathrm{~m} / \mathrm{s}$ & 5.0 & 12.4 & 24.8 & 37.2 & 49.6 \\
\hline
\end{tabular}

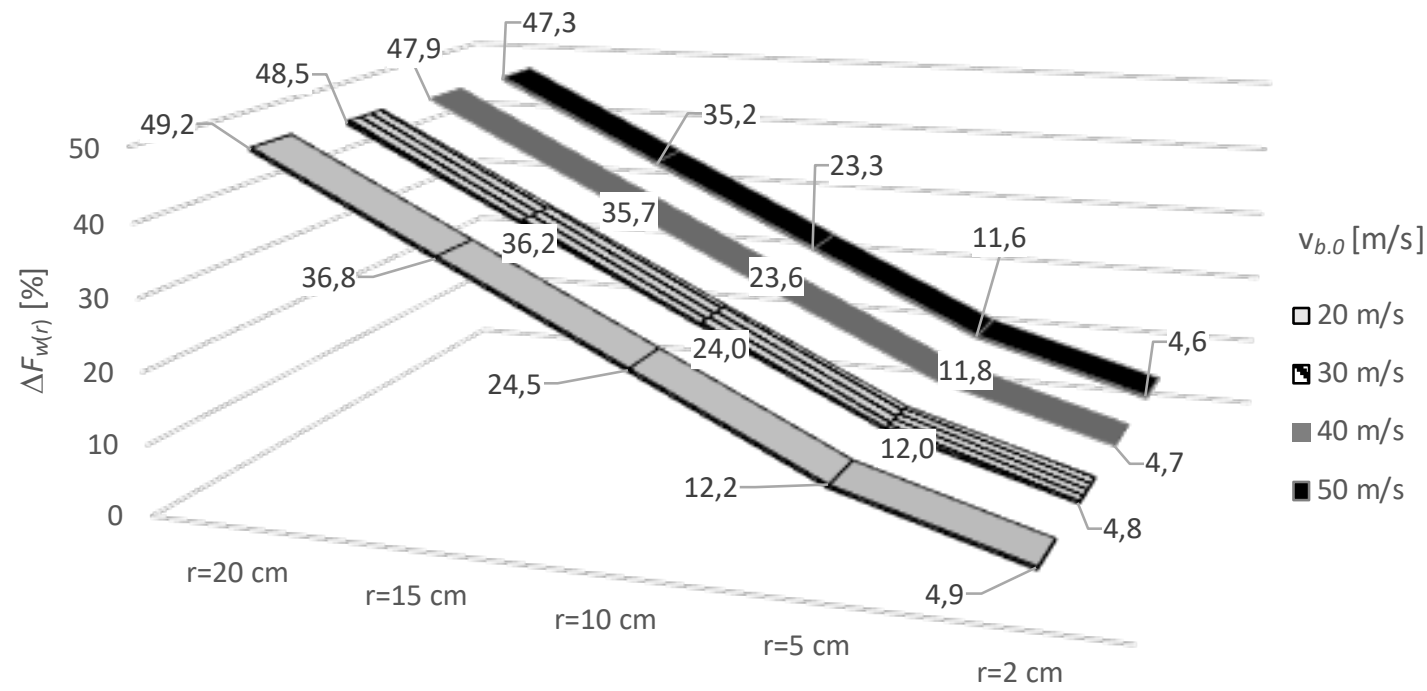

Figure 6. The total wind force reduction $\Delta F_{w(r)}[\%]$ on bridge pier of $h=20 \mathrm{~m}$ placed in TC $I$, in dependance on wind velocity $v_{b .0}$ and radius $r$ 


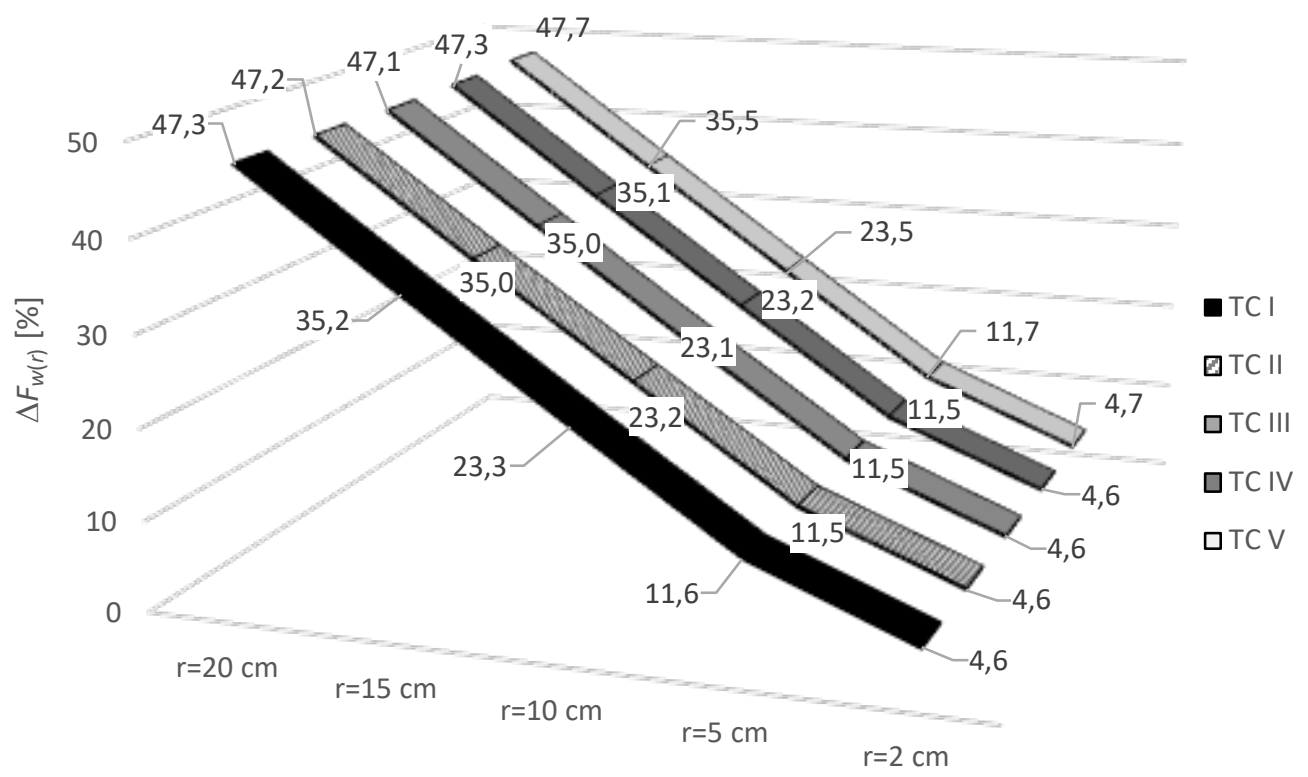

Figure 7. The total wind force reduction $\Delta F_{w(r)}$ [\%] on bridge pier of $h=20 \mathrm{~m}$ exposed to wind velocity of 50 $\mathrm{m} / \mathrm{s}$ in dependance on terrain category TC and radius $r$

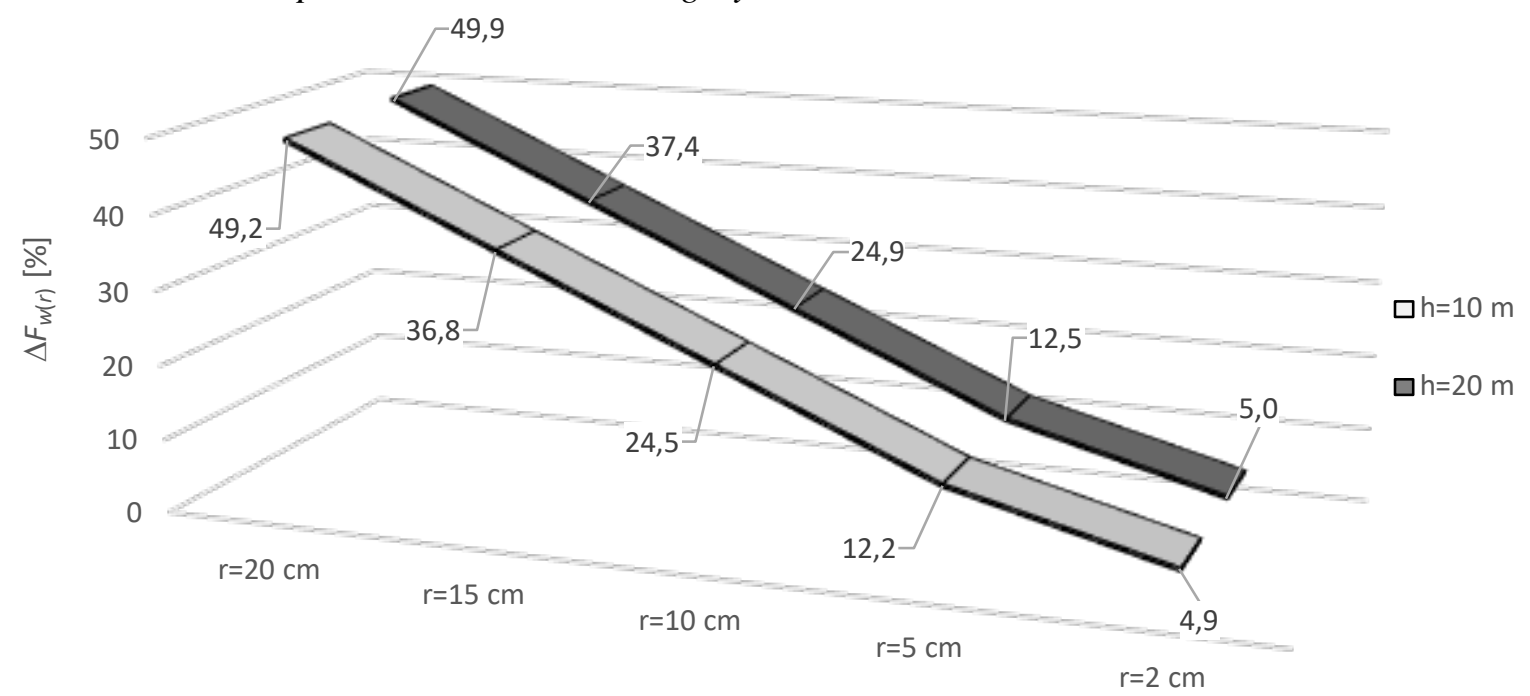

Figure 8. The total wind force reduction $\Delta F_{w(r)}[\%]$ on bridge pier placed in TC I exposed to wind velocity of $20 \mathrm{~m} / \mathrm{s}$ in dependance on bridge height $h$ and radius $r$

Table 11. Comparison of total wind force reduction $\Delta F_{w(r)}[\%]$, reduction of area $\Delta A_{(r)}[\%]$ and reduction of moment of inertia $\Delta I_{(r=0)}$ in relation to $r$

\begin{tabular}{|c|c|c|c|}
\hline$r[\mathrm{~cm}]$ & $\Delta A_{(r)}[\%]$ & $\Delta I_{(r)}[\%]$ & $\Delta F_{w(r)}[\%]$ \\
\hline 2 & $\approx 0$ & 0.1 & $4.6-5.0$ \\
\hline 5 & 0.2 & 0.6 & $11.5-12.5$ \\
\hline 10 & 0.9 & 2.4 & $23.1-25.0$ \\
\hline 15 & 1.9 & 5.1 & $35.0-37.5$ \\
\hline 20 & 3.4 & 8.6 & $47.1-49.9$ \\
\hline
\end{tabular}

For non-hollow cross sections of $b / d=100 / 100 \mathrm{~cm}$ with rounded corners of $2 \mathrm{~cm}$ and $5 \mathrm{~cm}(2 \%$ and $5 \%$ of the wind exposed pier width) the total wind forces are smaller by up to $5 \%$ and $12,5 \%$, 
respectively, with negligible reduction of the cross sectional properties in relation to sharp corner cross section (less than 1\%). For the radii of 10 and $15 \mathrm{~cm}$ (10\% and $15 \%$ of the wind exposed pier width) with very little loss of load bearing properties (the cross sectional area are smaller $0.9 \%$ and $1.9 \%$, the moment of inertia are smaller 2.4 and 5.1\%, respectively) the reduction in total wind force are significant: up to $25 \%$ and $37.5 \%$, respectively.

The greatest total wind force reduction of almost $50 \%$ is achieved when rounded part is $20 \%$ of the wind exposed width $(r / b=20 / 100 \mathrm{~cm})$ with $3.5 \%$ reduction in area and $8.6 \%$ reduction in moment of inertia.

\section{Conclusion}

As it is written in introduction, the careful design may reduce wind load on structural elements, such as bridge piers. By rounding the corners of square non-hollow cross section of pier, the total wind force on pier in free standing phase can be drastically reduced in comparison to total wind force on pier with sharp corners (up to $50 \%$ for $r / b=0.2$ ) with small reducing in load bearing properties of the pier (3.5\% reduction in area and $8,6 \%$ reduction in moment of inertia).

Changes in bridge pier environment have negligible influence on changes in reduction of total wind force (up to $0.6 \%$ ), as well as changes in pier height and wind velocity.

For shorter pier, the reduction of total wind force is greater in relation to taller pier, but changes in total wind force reduction due to changes in pier height are in range of $0.1 \%$ to $2.2 \%$.

The relative difference in reduction in total wind force due to different wind velocity for all analysed cases is up to $1.9 \%$.

For engineering purposes it can be concluded that reduction in total wind force on pier with cross sections with rounded corners in comparison to total wind force on pier with cross sections with sharp corners primarily depends on corner design. Influence of wind velocity, terrain category and pier height does not change much the total wind force reduction due to rounding the corners of pier cross section.

\section{Acknowledgements}

This paper is a part of research supported by University of Rijeka through the grant No. 13.05.1.1.01. and grant No. uniri-tehnic-18-127. The authors are grateful for this support.

\section{References}

[1] Harris, J.: The Tallest Tower: Eiffel And The Belle Epoque, Unlimited publishing, Bloomington, Indiana, USA, 2004.

[2] Larsen, A., Larose, G. L.: Dynamic wind effects on suspension and cable-stayed bridges, Journal of Sound and Vibration, 334 (2015), 6, 2-28.

[3] Xu, Y.-Z.: Wind Effects on Cable-Supported Bridges, John Wiley \& Sons, Singapore, 2013.

[4] Xie, X., Li, X., Shen, Y.: Static and Dynamic Characteristics of a Long-Span Cable-Stayed Bridge with CFRP Cables, Materials, 7 (2014) 6, 4854-5877.

[5] Borri, C., Costa, C.: Bridge Aerodynamics and Aeroelastic Phenomena, Stathopoulos T., Baniotopoulos C.C. (eds) Wind Effects on Buildings and Design of Wind-Sensitive Structures, Vol. 493, CISM International Centre for Mechanical Sciences, Springer, Vienna, 2007.

[6] Han, Y., Chen, Z.-Q., Hua, X.-G., Feng, Z.-Q., $\mathrm{Xu}, \mathrm{G}$. J.: Wind loads and effects on rigid frame bridges with twin-legged high piers at erection stages, Advances in Structural Engineering, 20 (2017), 10, 1586-1598.

[7] Hastak, M., Mirmiran, A., Miller, R., Shah, R., Castrodale, R.: State of Practice for Positive Moment Connections in Prestressed Concrete Girders Made Continuous, Journal of Bridge Engineering, 8 (2003), 5, 267-272.

[8] Sesar, P.: Optimizing of Continuous Bridge Connections, Doctoral Thesis, Faculty of Civil Engineering, J. J. Strossmayer University of Osijek, Osijek, Croatia, 2005. (in Croatian).

[9] Buljac, A., Kozmar, H., Pospíšil, S., Macháček, M.: Aerodynamic and aeroelastic characteristics of typical bridge decks equipped with wind barriers at the windward bridgedeck edge, Engineering Structures, 137 (2017), 310-322.

[10] Kozmar, H., Procino, L., Borsani, A., Bartoli, G.: Optimizing height and porosity of roadway 
wind barriers for viaducts and bridges, Engineering Structures, 81 (2014), 49-61.

[11] Štimac Grandić, I., Ivančić, A., Liker, B.: Parametric analysis of wind action on slab bridge deck, Engineering Review, 31 (2011), 1, 45-54.

[12] Wardlaw, R. L.: Wind effects on bridges, Journal of Wind Engineering and Industrial Aerodynamics, 33 (1990), 1-3, 301-312.

[13] Martínez, F. J., González-Vidosa, F., Hospitaler, A., Yepes, V.: Heuristic optimization of $R C$ bridge piers with rectangular hollow sections, Computers and Structures, 88 (2005), 5-6, 375-386.

[14] Hjorth-Hansen, E., Jakobsen, A., Strømmen, E.: Wind buffeting of a rectangular box girder bridge, Journal of Wind Engineering and Industrial Aerodynamics, 42 (1992), 1, 12151226.
[15] Masaki, Y., Sano, S., Sakai, F.: Analysis and Design of Wind- and Earthquake-Resistance of an S-Curved Cable-Stayed Bridge, Proc. of Bridges and Transmission Line Structures, ASCE Structure Congress, Orlando, Florida, USA, 1987, 341-356.

[16] Matsuzaki, M., Ushio, M., Nanjo, M., Kumagai, A., Nakazak, R., Tanaka, H.: WindInduced Vibration in Suspension Bridge Towers and its Control Measures, Hitachi Zosen Technical Report, 88-98, 1986.

[17] EN 1991-1-4 Eurocode 1: Actions on structures - Part 1-4: General actions - Wind actions (EN 1991-1-4:2005+AC:2010+A1:2010), CEN, Brusseles, 2010.

[18] Hurty, W. C., Rubinstein, M. F.: Dynamics of Structures, Prentice-Hall, New Delhi, 1967. 